KOSELLECK AND THE MARGINS OF HISTORY:

ANACHRONISM, MEMORY, LATENCY.

\title{
Koselleck y los márgenes estéticos de la historia: anacronismo, memoria y latencia
}

Antonio Rivera García

Universidad Complutense de Madrid

antonio.rivera@pdi.ucm.es - http://orcid.org/0000-0002-4559-9171

Fecha recepción: 29.05.2020 / Fecha aceptación: 16.10.2020

\section{Resumen}

Anacronismo, memoria y latencia, que en el pasado fueron expulsados hasta los márgenes del discurso historiográfico, pueden ser de gran utilidad para comprender la historia que se abre tras la crisis de la modernidad. La obra de Koselleck no solo proporciona las principales claves para elaborar el «régimen de historicidad» moderno, sino también ayuda a comprender estos tres conceptos «marginales». Como historiador de la «contemporaneidad de lo no contemporáneo» nos lleva a pensar en hechos y conceptos adelantados y atrasados en relación con la época en que aparecen. En sus estudios sobre los monumentos a los caídos ha descubierto nuevas manifestaciones históricas en las que el sentido del pasado ya no depende del futuro. Y, en polémica con Gadamer, ha abierto la posibilidad de explicar la historia con categorías que no

\section{Abstract}

The concepts anachronism, memory and latency, which in the past were pushed to the margins of historiographical discourse, can be extremely useful in understanding the history that unfolds after the crisis of modernity. Koselleck's work not only provides the main keys to develop the modern "regime of historicity", but also helps to understand these three "marginal" concepts. As a historian devoted to the "contemporaneity of the non-contemporary", he suggests facts and concepts that are both ahead of and behind the time in which they appeared. In his studies about war memorials he has found new historical expressions in which the meaning of the past no longer depends on the future. Furthermore, in disagreement with Gadamer, he has raised the possibility to explain history through categories that are not subject to herme- 
Monográfico | Koselleck y los márgenes estéticos de la historia: anacronismo, memoria y latencia

pasan por la hermenéutica. A este tipo pertenece la Stimmung de latencia, con la que Gumbrecht piensa el final del cronotopo moderno.

\section{Palabras clave}

Anacronismo, Begriffsgeschichte, memoria, monumentos, latencia, Stimmung, modernidad, postmodernidad neutics. The Stimmung of latency Gumbrecht uses to reflect on the end of the modern chronotope belongs to this type of categories.

\section{Keywords}

Anachronism, Begriffsgeschichte, memory, memorials, latency, Stimmung, modernity, postmodernity. 
ANACRONISMO, MEMORIA y LATENCIA son categorías que con frecuencia se han colocado en los márgenes del discurso histórico o de la reflexión sobre la historia. El anacronismo se ha rechazado por ser el «pecado original» de los historiadores; la memoria histórica ha sido menospreciada por ser un mero contenedor de recuerdos subjetivos; y la latencia se ha ignorado porque alude a una categoría que, por resultar ajena a la hermenéutica o a la interpretación lingüística, se relaciona más con lo inefable que con la expresión de los fenómenos históricos. Estas categorías han tenido, sin embargo, una gran importancia para la estética y sobre todo para el análisis del arte contemporáneo. En muchas ocasiones, el arte realizado después de Auschwitz ha reflejado, antes incluso que la ciencia histórica, la crisis de los conceptos fundamentales de la modernidad. En este contexto, el anacronismo, la memoria y la latencia han adquirido gran importancia. Por eso pensamos que también pueden ser de gran utilidad para la historiografía y la filosofía de la historia que abordan la crisis de los tiempos modernos.

Hoy ya no es posible pensar en la historia sin tener en cuenta los usos, sean o no discursivos, adelantados y atrasados en relación con las instituciones y conceptos hegemónicos de su época. Los hechos, creencias y conceptos que rompen con el «espíritu del tiempo», y que muchas generaciones de historiadores rechazaron por ser anacrónicos, impiden pensar en la historia como una sucesión de épocas homogéneas, sin conflictos y desajustes, y en esa noción universal o unilineal de la historia, que es propia de la filosofía moderna. Los ejercicios actuales de memoria histórica, así como el papel central que desempeña la figura del testigo, ponen de relieve que los recuerdos individuales aspiran a la objetividad, a su inscripción en los textos de historia. Por eso, el impostor es el principal enemigo de esta memoria archivística e historiadora. Asimismo, la extensión de la Stimmung de latencia, esto es, la sustitución del tiempo acelerado de la modernidad por un tiempo congelado o estancado, certifica el final de la historia universal y de la confianza moderna en el progreso, en la pronta emancipación de la humanidad y en la eficacia política de sus conceptos «futurocéntricos». A pesar de que la obra de Koselleck no ha pensado en el fin de la modernidad en estos términos, sus ensayos nos ayudan, como comprobaremos en las siguientes páginas, a repensar estas categorías que han tenido una enorme importancia para el arte y la estética contemporáneas y que, sin embargo, han adquirido tradicionalmente un papel «marginal» dentro de la disciplina histórica. 


\section{1. «El pecado de los pecados»" del historiador: el anacronismo}

Por regla general, los historiadores solo aceptan el anacronismo si queda confinado dentro del ámbito «irracional» del arte, y, en especial, dentro de movimientos artísticos que, como el surrealista, tienen una honda relación con lo onírico. Nuestra hipótesis dice lo siguiente: el anacronismo deja de tener una centralidad negativa para una concepción de la historia -quizá podemos llamarla "poshistoria»- que no solo rompe con la linealidad de la historia universal, con la clara distinción entre épocas que se suceden y dejan atrás el pasado, integrando sus elementos más valiosos, sino también con una noción de la historia que piensa en cada época como un universo mental, fijo y no conflictivo.

La regla de oro del historiador que lucha contra el anacronismo dice que se debe situar un hecho, un personaje, un uso discursivo, dentro de aquella época a la que pertenece, y no en un periodo distinto al que le corresponde o conviene. Generalmente, el anacronismo -y a ello hace referencia el prefijo «ana-»- suele ir de delante hacia atrás, del presente hacia el pasado ${ }^{2}$. Citemos a este respecto el famoso ejemplo dado por Lucien Febvre y tomado de los surrealistas: "César muerto por el disparo de una browning". Proyectamos entonces nuestras propias realidades sobre el pasado. En cambio, si el movimiento ya no es de retroceso, sino de atrás hacia delante, del pasado hacia el presente o hacia el futuro, hablamos -para utilizar la terminología de Warburg- de supervivencia (Nachleben).

$\mathrm{El}$ anacronismo parece ridículo cuando nos referimos a hechos u objetos como el de la pistola en la Antigua Roma, pero este asunto empieza a complicarse cuando se trata de pensamientos y de creencias. El anacronismo puede definirse como un elemento «fuera de lugar» porque no se puede integrar dentro de la época donde se presenta. Le conviene, frente a la hegeliana y moderna filosofía de la historia, una dialéctica sin síntesis, pues se produce un choque o conflicto entre ese elemento y la época donde aparece. Si el historiador reconociera el anacronismo o el conflicto citado, ni sería posible un conocimiento sistemático, es decir, no se podría cerrar, completar, el saber sobre una época, ni, aún menos, una noción universal, unilineal y progresiva de la historia como la que nos propone la filosofía moderna.

Hasta ahora, los estudios estéticos y la historia del arte son las disciplinas que más valor han otorgado a los anacronismos, sobre todo cuando abordan las vanguardias y la supervivencia de elementos supuestamente superados. Frente al método del «artista y su tiempo», el anacronismo nos invita a explorar el significado del «artista contra su tiempo» ${ }^{3}$. Que todo ello se dirige contra la filosofía de la historia moderna o el régimen de historicidad moderno, aparece perfectamente expuesto en la obra del poeta y cineasta Pasolini. En concreto, su filme Medea (1969) proporciona una magnífica imagen de la disolución o integración del anacronismo por una nueva noción de la historia. En una escena que transcurre en Corinto, pero rodada en realidad en la renacentista Pisa, el centauro mítico (mitad bestia, mitad hombre),

1. L. Febvre, Le problème de l'incroyance au XVIe siècle. La religion de Rabelais, París, 1942, 6.

2. J. Rancière "Le concept d'anachronisme et la verité de l'historien", L'inactuel, 6, 1996, 54.

3. G. Didi-Huberman, Ante el tiempo. Historia del arte y anacronismo de las imágenes, Buenos Aires, 2011, 43. 
un elemento de otro tiempo, aparece al lado del centauro moderno (todo hombre), de otro elemento perteneciente a la nueva época de la razón, ya se identifique ésta con la polis griega, con la ciudad renacentista o con la ilustrada. El cineasta, al poner uno al lado del otro, quiere expresar que el nuevo centauro no ha suprimido al antiguo, que permanece este supuesto anacronismo en una nueva época que se declara contraria a los mitos. En un poema que escribe en Capadocia, mientras esperaba la llegada de la estrella de Medea, expone también esta visión conflictiva de la historia que relaciona, sin síntesis, elementos contrarios, pertenecientes a épocas distintas. En estos versos dice que no se puede hacer la historia del hombre «real» de su tiempo sin yuxtaponer elementos diferentes o antitéticos, ya que este hombre es el resultado tanto de la racional evolución de las cosas - de la superación y síntesis de elementos del pasado- como de la subsistencia de elementos considerados anacrónicos por ser contrarios al espíritu racional de su tiempo ${ }^{4}$.

En el fondo, no se puede pensar ninguna época, ningún presente, sin anacronismos, sin el entrecruzamiento de los tiempos, como de algún modo nos invita a pensar la teoría de los estratos del tiempo de Koselleck. Por eso habría que comenzar criticando al gran enemigo del anacronismo, Lucien Febvre, cuando al inicio de El problema de la incredulidad en el siglo XVI habla de la historia como «hija del tiempo», como la sucesión de épocas dotadas, cada una de ellas, de un universo mental determinado, con sus cualidades, inclinaciones y curiosidades, con sus creencias específicas ${ }^{5}$.

Este pensamiento sobre las épocas pone de relieve que este historiador de la conocida escuela de los Annales no ha reflexionado sobre la historicidad radical del ser humano, sobre el tiempo en sí mismo. Este historiador ha convertido el tiempo en imagen de su contrario, esto es, en imagen de la eternidad en la que cada cosa está definitivamente en su lugar. Desde este enfoque, la historia desemboca en «metahistoria» porque el tiempo de la cronología, del suceder temporal, depende de un tiempo sin cronología, puro presente o eternidad. En el fondo, tanto la filosofía de la historia y el concepto de historia universal como una buena parte de la historiografía moderna dependen de la teología o del mito histórico de la redención del tiempo. Tal redención consiste en abolir la sucesión o el devenir como tal, en suprimir la historicidad radical, y en hacer que el tiempo se asemeje a aquello de lo cual es copia, si-

4. Así lo expresa P.P. Pasolini en el poema Callas, que escribe en Capadocia, en junio de 1969, unos días antes de que llegue la diva al rodaje de Medea: "Las superaciones, las síntesis! Ilusiones.../ Digo, de europeo vulgar, pero sin el menor cinismo/ [...] La tesis y la antítesis coexisten con la síntesis: he aquí/ la verdadera trinidad del hombre ni prelógico ni lógico,/ sino real. Sé, pues, sabio con tus síntesis/ que te permiten avanzar (y progresar) en el tiempo (que no existe),/ pero sé igualmente místico, frente a frente democráticamente/ en el mismo tabernáculo, con síntesis, tesis y antítesis." (Cit. en J. Duflot, Conversaciones con Pasolini, Barcelona, 1971, 188-189).

5. El fragmento donde aparece esta tesis es el siguiente: "Histoire, fille du temps. [...] chaque époque se fabrique mentalement sa représentation du passé historique. [...] Elle le fabrique avec ses dons à elle, son ingéniosité spécifique, ses qualités, ses dons et ses curiosités, tout ce qui la distingue des époques précédentes.” (L. Fevbre, Le problème..., op. cit., 2). Cfr. G. Didi-Huberman, Ante el tiempo..., op. cit., 52. 
guiendo, en el fondo, la estela -como advierte Rancière ${ }^{6}$ - del Timeo platónico: «el tiempo es la imagen móvil de la eternidad inmóvil».

La redención del tiempo puede hacerse al estilo de la filosofía de la historia, y entonces se trata de someter el devenir a un orden lógico de causas y efectos, de supeditar el tiempo a leyes universales, de establecer una concatenación necesaria entre los acontecimientos, todo lo cual debe conducir a un final emancipador. Esta filosofía es lo contrario del "historiar primigenio» de griegos y romanos ${ }^{7}$, y se acerca al modelo poético de Aristóteles, para quien la poesía, en contraste con la historia, tenía un estatuto más filosófico porque integraba la pluralidad de acciones dramáticas dentro de una única totalidad articulada ${ }^{8}$. Lo que no prevé la filosofía moderna, la cual confía en el progreso acelerado hacia el final emancipador, es que el tiempo se detenga, que se produzca un estancamiento, sin haber alcanzado su objetivo. La postmodernidad comienza precisamente cuando la confianza en el progreso deja de ser la «creencia ${ }^{9}$ fundamental, decisiva, que explica las acciones de los hombres de una época.

La redención del tiempo puede hacerse asimismo al estilo de Febvre, el historiador de los Annales, que, con su reconocimiento del tiempo largo de los ciclos y de las estructuras y con su profundización en lo social, nos ofrece el modelo del tiempo cuajado, inmovilizado, en épocas. La historia es así la sucesión de épocas homogéneas, dentro de las cuales no cabe apreciar un verdadero devenir ni conflicto. Se entiende entonces que Febvre combata la posición de aquellos que sostienen que hay gente adelantada o atrasada a su tiempo. Este es el caso de Lefranc, quien en el prefacio de su edición de Pantagruel hablaba de los adelantados a su época y por ello cometía el «pecado» de anacronismo, es decir, deshacía la visión de la época como un todo cerrado, dentro del cual no es posible aquello que se sale de las creencias compartidas en su tiempo ${ }^{10}$. Febvre sostiene a este respecto que el trabajo fundamental del historiador consiste en salir del universo mental del propio historiador para comprender el de la época estudiada, que es una especie de sistema acabado sobre el cual no cabe esperar ningún desajuste con el «espíritu del tiempo», ninguna sorpresa o, en definitiva, ningún anacronismo ${ }^{11}$. Con independencia de que cometa el error de pensar que es posible distinguir entre sujeto histórico e historiador, Febvre ya no se pregunta si es verdad que se ha producido tal hecho o pensamiento, sino si era posible que se produjera. No es así concebible la «herejía» que implica salirse del "espíritu del tiempo». El actor o agente histórico debe parecerse necesariamente a su época y poseer las creencias de su tiempo. De este modo, Rabelais no pudo ser un descreído porque el siglo XVI fue un periodo enteramente determinado por la religión cristiana. Y, en cambio, el sermón de la montaña sí fue posible porque el ideal que

\footnotetext{
6. J. Rancière, “Le concept..., op. cit., 55-56.

7. K. Löwith, El hombre en el centro de la historia. Balance filosófico del siglo XX, Barcelona, 1998, 317.

8. J. Rancière, “Le concept...”, op. cit., 56.

9. Sobre la importancia de las creencias para explicar una época, véase "Historia como sistema” de J. Ortega y Gasset, Obras Completas, 6, Madrid, 1983, 13-15.

10. J. Rancière, “Le concept...”, op. cit., 57-58.

11. G. Didi-Huberman, Ante el tiempo..., op. cit., 53.
} 
contenía -escribe Paul Veyne en Le pain et le cirque, que en esta cuestión no se diferencia de Febvre $^{12}$ - ya se encontraba entre las creencias de los judíos del tiempo de Jesús.

La pertenencia a un tiempo, a una época particular, condiciona todo lo que puede existir. Al actuar de esta manera, la ciencia histórica práctica sin saberlo una «poética de la verosimilitud» ${ }^{13}$, ya que, al pretender demostrar que un pensamiento no puede desarrollarse allí donde no conviene, sustituye la verdad por lo verosímil. El desvelamiento de esta retórica, que la ciencia histórica suele ocultar, nos permite sostener, en primer lugar, que supone un uso indebido de las categorías de lo posible y del tiempo decir que Rabelais no pudo ser descreído porque su época no permitía esta posibilidad. Sí resulta, en cambio, aceptable dudar, ateniéndonos a las creencias de su tiempo y a su biografía, que Rabelais no fuera creyente. Y, en segundo lugar, el desvelamiento de la retórica de la verosimilitud nos permite afirmar que la historia siempre está abierta a la «herejía» en su sentido original; esto es, siempre se puede separar de las creencias de su tiempo, y, por lo tanto, puede tomar en consideración creencias y pensamientos adelantados o atrasados a su época ${ }^{14}$.

Koselleck nos permite alejarnos de esta retórica de la verosimilitud al introducir una mayor complejidad con sus categorías de la Begriffsgeschichte, y, en particular, con la noción de estratos del tiempo. Koselleck es el pensador de la «contemporaneidad de lo nocontemporáneo» porque, con la ayuda de esa teoría de los estratos temporales, cuestiona la linealidad de la historia universal, pero sin incurrir en el tiempo circular, detenido en suma, del mito. Por un lado, tiene en cuenta que, sobre todo en la modernidad, son frecuentes los hechos y conceptos adelantados a su tiempo; y, por otro, pone fin a la clara distinción entre épocas que se suceden y dejan atrás el pasado, tras integrar sus elementos más valiosos: el pasado -los elementos que se repiten, continúan o se recuperan- sigue actuando sobre el presente. Se manifiesta así contrario a una noción de la historia, que, como la de Febvre, piensa en cada época como si fuera un universo mental fijo y no conflictivo.

En relación con la «Historia de los conceptos», Koselleck rechaza la idea de Otto Brunner, uno de los coordinadores del Geschichtliche Grundbegriffe, de que el lenguaje de las fuentes basta para explicar las mismas fuentes, de forma que se pueda estudiar el pasado con las mismas categorías del pasado. No es cierto que los contemporáneos de los hechos y discursos pretéritos se conozcan a sí mismos mejor que sus descendientes o que los historiadores del presente. Muchas cosas solo pueden apreciarse después de haber transcurrido un cierto tiempo, y a veces es conveniente tomar distancia y escapar del cosmos o de la mentalidad de los contemporáneos a los hechos y discursos estudiados.

En contra del ideal del "espíritu del tiempo», Koselleck nos ha enseñado que conceptos y hechos pueden ser elaborados y suceder "contra su tiempo». La obsesión por no incurrir en anacronismos puede llevar a no tener en cuenta los cambios y novedades, que son siempre contra su tiempo, ni la reaparición en el presente de elementos del pasado que

12. J. Rancière, “Le concept..., op. cit., 61.

13. J. Rancière, “Le concept..., op. cit., 64.

14. J. Rancière, “Le concept..., op. cit., 63. 
se pensaba definitivamente superados. Los estudios metodológicos de Koselleck, debido a la atención prestada a los tres niveles de temporalidad (duración, cambio, novedad) y a la doble dimensión de índice y factor de los conceptos, nos permiten captar la contemporaneidad de lo no-contemporáneo y cuestionar la obsesión por eliminar el anacronismo en el sentido al que nos referimos en estas páginas, esto es, como presencia de elementos contrarios al «espíritu del tiempo».

La Begriffsgeschichte de Koselleck, la historia conceptual de las prácticas discursivas, proporciona muchos ejemplos de «contemporaneidad de lo no contemporáneo». Nos muestra que hay discursos o conceptos tanto adelantados como atrasados a su tiempo. Resulta así frecuente que el tiempo de los conceptos no coincida con el de la historia de las estructuras o instituciones sociales. El carácter «adelantado» del concepto puede tener que ver con dos circunstancias: con la de que los conceptos sean factores que anticipan el futuro (vorausschauende Begriffe) y con el problema de la perspectiva o del punto de vista. Es posible, en primer lugar, que los conceptos, por dominar su dimensión de factor sobre la de índice, hagan presentes estratos de contenido futuro. Está claro a este respecto que la dimensión de factor del concepto de «soberanía» dominaba sobre la de índice cuando fue forjado por Hobbes a mediados del siglo XVII en Inglaterra. Tal concepto apareció en un contexto de guerras civiles en el que se cuestionaba incluso la autoridad limitada (premoderna) de los magistrados supremos.

La historia conceptual debe tener en cuenta, en segundo lugar, los elementos y conceptos del presente con los cuales el historiador intenta comprender el pasado. Se trata de concepciones, valores, análisis, etc. del presente que el historiador lleva a la época pretérita estudiada. Este anacronismo resulta inevitable cuando abordamos la cuestión del unilateralismo o del punto de vista de un historiador que también está dentro de la historia. Desde los escritos metodológicos de Weber, realizados en un contexto de crítica del realismo omniabarcante marxiano, la cuestión del punto de vista de las ciencias sociales ha sido planteada a menudo en el pensamiento alemán ${ }^{15}$. Resulta imposible contar o explicar un hecho histórico sin un determinado punto de vista que, inevitablemente, será unilateral, subjetivo y contemporáneo. Por esta razón, no existe un pasado inmóvil, fijo, definitivo. Se trata, por el contrario, de algo en movimiento porque depende de la construcción, de la imaginación, de ese sujeto histórico, en constante cambio, que es el historiador.

El problema del punto de vista también se ha planteado en el contexto francés. Se puede apreciar con claridad en la crítica que Castoriadis realiza a la determinista y unilineal filosofía de la historia marxista. Sostiene el filósofo francés que todo historiador, lejos de convertirse

15. Sobre el tema del punto de vista cabe citar sobre todo "La objetividad cognoscitiva de la ciencia social y de la política social” de M. Weber, Ensayos sobre metodología sociológica, Buenos Aires, 1973. Sobre la historia del punto de vista, que puede remontarse hasta el Renacimiento con Comenius y Zedler, resulta fundamental referirnos al capítulo "Compromiso con la situación y temporalidad" de R. Koselleck, Futuro pasado. Para una semántica de los tiempos históricos, Barcelona, 1993. Fuera del ámbito alemán, también nos parece pertinente mencionar las reflexiones que sobre la doctrina del punto de vista aparecen en el capítulo IX de "El tema de nuestro tiempo" de J. Ortega y Gasset, Obras completas, 3, Madrid, 1983. 
en una conciencia trascendental, es un sujeto histórico, y por ello el conocimiento que adquiere nunca puede tener el estatuto de un saber acabado. Cuando se olvida que el saber histórico es necesariamente parcial y provisional, acabamos en el «sociocentrismo», en la creencia de que una determinada sociedad o cultura constituye el centro del mundo. Cometemos entonces el error de pensar que se puede elaborar un discurso histórico sin anacronismo y que las proyecciones del presente sobre el pasado valen como verdades íntegras, exhaustivas y sistemáticas. No obstante, Castoriadis, al igual que Koselleck, advierten que no debe confundirse "esta idea con las afirmaciones del escepticismo o del relativismo inocente"16.

Según Castoriadis, Marx no consigue al final superar el sociocentrismo comentado. No llega a reconocer que todo saber histórico tiene forzosamente un valor provisional por la presencia de elementos anacrónicos, esto es, por colocar algo del presente en el análisis o visión del pasado. Resulta así inevitable que proyectemos intereses, preocupaciones, valores, del mundo contemporáneo sobre el pasado estudiado. Castoriadis escribe a este respecto lo siguiente: «La paradoja de la historia consiste en que cada civilización, por el hecho de que es particular y dominada por sus propias obsesiones, llega a evocar y a desvelar en las que la preceden o la rodean significaciones nuevas» ${ }^{17}$. Una paradoja que ya Goethe, como nos recuerda Koselleck, había advertido con claridad cuando decía que la historia debe reescribirse cada cierto tiempo, no porque se descubran nuevos hechos, sino «porque se dan nuevas opiniones, porque el que disfruta de una época que progresa es conducido a un punto de vista desde el que puede abarcar y enjuiciar lo pasado de una forma nueva» ${ }^{18}$.

La conclusión a la que llega Castoriadis es la misma que la de Weber: no se puede superar el unilateralismo porque «jamás veré nada desde todos los lugares posibles a la vez». Y esto, en lugar de ser un «defecto de nuestra visión, "es" la visión. El resto -concluye Castoriadis- es el fantasma eterno de la teología y de la filosofía» ${ }^{19}$. La «"visión total” de la historia», el punto de vista omniabarcante, no es más que el «fantasma teológico» de la historia. Según Castoriadis, los marxistas más ortodoxos de su tiempo todavía creían en este fantasma, bien porque pensaban poseer esa visión total, bien porque postulaban que en una sociedad socialista desaparecería el sociocentrismo, el anacronismo, el punto de vista o, en definitiva, la mezcla del particular universo mental del historiador con el de las épocas pretéritas.

La cita anterior de Goethe pone de relieve que el problema del punto de vista está conectado con el de la «reescritura» de la historia. Koselleck sostiene que, en relación con el manejo de las fuentes, se abren tres posibilidades para la reescritura ${ }^{20}$. Pueden aparecer, en primer lugar, nuevos testimonios porque se encuentren fuentes perdidas. Es posible, en segundo lugar, que «nuevas cuestiones contribuyan a buscar y encontrar nuevos testimonios». Así sucedió cuando la historia del derecho se apartó de las fuentes puramente

16. C. Castoriadis, La institución imaginaria de la sociedad, Barcelona, 2013, 55.

17. C. Castoriadis, La institución..., op. cit., 58.

18. R. Koselleck, Futuro pasado..., op. cit., 190-191.

19. C. Castoriadis, La institución..., op. cit., p. 65.

20. R. Koselleck, Los estratos del tiempo: estudios sobre la historia, Barcelona, 2001, 76-77. 
narrativas y empezó a centrarse en «documentos, actas e inscripciones». Finalmente, «los testimonios de que se dispone pueden ser leídos o interpretados nuevamente». A esta tercera posibilidad, que puede darse solo por la mera sucesión generacional, se referían Castoriadis y Goethe. Lo cierto, añade Koselleck, es que hoy se utilizan y combinan al mismo tiempo los tres procedimientos.

El anacronismo inherente al punto de vista tiene, por lo demás, una extraordinaria función heurística, similar a la que puede tener la retórica, las metáforas y metonimias, en los distintos saberes humanos. Como ya señalara Weber ${ }^{21}$, la ciencia necesita de elementos ajenos para resolver asuntos tan esenciales como saber lo que es digno de ser conocido de la realidad infinita. La realidad misma no nos dice qué hechos y discursos son los más relevantes para el científico y el historiador. Así que el punto de vista, unido siempre a los valores morales y políticos de una época, no solo sirve para seleccionar de la realidad el objeto digno de estudio, sino que permite introducir nuevas significaciones y campos de estudio. La estética y la historia del arte nos proporcionan numerosas muestras de ello ${ }^{22}$, pero también en otros ámbitos se puede apreciar la importancia del cambio del punto de vista para el surgimiento de nuevas temáticas. Está claro, por ejemplo, que el interés por los fenómenos heréticos, desde el marranismo al protestantismo, en la historiografía española actual está unido a valores políticos y religiosos que no eran compartidos por historiadores de otros periodos.

En relación con los hechos y discursos «retrasados» con respecto a su tiempo, Koselleck reconoce que existe toda una serie de «constelaciones repetibles, efectos a largo plazo, actitudes arcaicas que perviven, regularidades en la serie de los acontecimientos», que pone de relieve que «la historia del tiempo presente, elevada a la categoría de concepto, es más que la historia de nuestro tiempo presente» ${ }^{23}$. Con estas palabras, el historiador alemán hace referencia a algo del pasado que se coloca en el presente, y que, sin embargo, desde una

21. M. Weber, Ensayos..., op. cit., 67.

22. Según Didi-Huberman (Ante el tiempo..., op. cit., 265 ss.), el anacronismo permite descubrir o inventar nuevos objetos históricos: "Sólo toma sentido en la historia lo que aparece como anacronismo, el anacronismo de una colisión donde el Otrora se encuentra interpretado y «leído», es decir, puesto al día por la llegada de un Ahora resueltamente nuevo". El mismo Didi-Huberman explica que anacronismo es ver la parte manchada de estrellas, perteneciente al fresco de la Virgen de las sombras de Fra Angelico, como semejante al arte de Pollock; y anacronismo es también situar en el mismo plano, como hace el gran crítico Carl Einstein, el cubismo y la Negerplastik. Lo cierto es que sin Pollock no se habría atendido a la importancia que tiene en Fra Angelico la dissimilitudo, en un artista cuya pintura suele, sin embargo, considerarse uno de los primeros hitos del arte renacentista basado en la mimesis, en lo contrario de la desemejanza. Y sin el cubismo, Carl Einstein no habría abierto un nuevo campo de estudio, el que resulta de mezclar dos disciplinas hasta entonces separadas: la etnografía y el estudio formalista del arte. Desde luego, anacronismo es decir que "César ha muerto del disparo de una browning", pues se falsifica la historia cuando se hace “"retroceder» un arma de fuego contemporánea hasta la antigüedad romana”. Pero otra cosa muy distinta añade Didi-Huberman (Ante el tiempo..., op. cit., 55)- es, cuando nos situamos en el plano del pensamiento o conceptual, y llevamos a la Antigüedad romana "un análisis de la conjura política buscando sus ejemplos -o sus supervivencias- en la época contemporánea”.

23. R. Koselleck, Los estratos..., op. cit., 133. 
concepción inmóvil del tiempo o de las épocas, podría ser rechazado por anacrónico. En el ámbito de la estética e historia del arte, Warburg es uno de los pensadores que ha explorado con mayor profundidad la supervivencia (Nachleben) del pasado, de algo que se creía arcaico, ya superado, y que, sin embargo, reaparece en nuestro presente ${ }^{24}$.

Es posible que se use conceptos de otras épocas con el objetivo de imponer o recuperar una institución, una creencia o una praxis consideradas obsoletas, y se haga de este modo presente estratos de contenido pasados, como sucede con el pensamiento reaccionario en la modernidad. Tomemos el ejemplo de la lucha de los reaccionarios españoles por retornar a una concepción tradicional de la monarquía y por devolver a la Iglesia católica el peso político que pierde con el triunfo de los regímenes liberales. Este caso demuestra que el uso de conceptos del pasado no siempre se relaciona con el fenómeno temporal de la «continuidad», ya que puede tener que ver con la «reacción», con un cambio que nos empuja hacia atrás, y no, como pretenden los modernos, hacia delante.

Pero también es posible el uso de conceptos del pasado para defender novedades. Así sucede en España durante los siglos XVIII y XIX, durante un tiempo en el que con frecuencia se utiliza conceptos considerados obsoletos para emprender las reformas que precisa la consolidación del Estado moderno. Una buena muestra de ello son las reincorporaciones a la Corona, en tiempos de Carlos III, del patrimonio alienado en siglos anteriores. Tales reincorporaciones, que eran necesarias para constituir una saneada y moderna Hacienda Pública, se propugnaron con la ayuda de conceptos políticos premodernos: Corona, regnum, pactum dominationis, etc. Es decir, servidores ilustrados como Campomanes hicieron uso de conceptos que ya eran utilizados por los representantes de la tradición, la nobleza y el alto clero, para defender sus privilegios e impedir las innovaciones del soberano. De ahí la aparente paradoja de utilizar los mismos conceptos antiguos, premodernos, que utilizaban los partidarios de la tradición y del statu quo, con el objetivo de socavar las instituciones seculares que impedían aumentar el poder discrecional del monarca y su real patrimonio. Esta paradoja puede ser debida, en unas ocasiones, a que se realiza la reforma desde una institución tradicional, como lo era el Consejo de Castilla presidido durante un tiempo por Campomanes; y, en otras, a la estrategia de hacer más fácil la aceptación de tales reformas por los sectores tradicionales. En este último caso, se utiliza conceptos antiguos, inadecuados para expresar las novedades introducidas, con la finalidad «retórica» de persuadir al público o al pueblo de la conveniencia de novedades. El Discurso preliminar a la Constitución de Cádiz, atribuido a Agustín Argüelles, sería un buen ejemplo de este uso retórico.

Todo ello nos permite comprender que, frente a la tesis del anacronismo como «pecado original» del historiador, la teoría koselleckiana sobre los estratos del tiempo y la historia conceptual exige que el historiador esté abierto a la «herejía» en sentido original, esto es, a la posibilidad de que los hechos y los discursos se separen de las creencias dominantes o comunes de su tiempo. El historiador debe tomar en consideración creencias y pensamientos

24. Véase G. Didi-Huberman, La imagen superviviente. Historia del arte y tiempo de los fantasmas según Aby Warburg, Madrid, 2009. 
que pueden ser considerados adelantados o atrasados con respecto a la época en la que se dan. Solo así podrá escapar de la trampa que supone la concepción «verosímil» de la historia.

\section{La expresión de la "memoria histórica» en los monumentos levantados en homenaje a las víctimas de la guerra}

Sobre la cuestión de la memoria de un país o de una nación, también resulta muy relevante lo que escribe Reinhart Koselleck en esa serie de ensayos o artículos, algunos de ellos muy polémicos, que abordan la inscripción del recuerdo de la guerra en monumentos dedicados a los caídos y a las víctimas en general ${ }^{25}$. En estos textos, Koselleck mezcla la reflexión histórica con inevitables análisis estéticos, pues la mejor expresión contemporánea de la memoria la hallamos en obras artísticas. Este hecho explica que a menudo la cuestión de la memoria se desplace hasta los «márgenes» de la historia, de modo que adquiera más relevancia en el ámbito de la estética que en el de la historiografía.

El concepto de «memoria colectiva», que fue forjado por Maurice Halbwachs y retomado y defendido por Pierre Nora $^{26}$, es rechazado por el historiador alemán porque todo recuerdo es personal o individual, es decir, está ligado a experiencias propias e intransferibles. No existe un sujeto colectivo que tenga recuerdos. Esta memoria compartida es una abstracción del mismo tipo que lo es la voluntad general o el Volksgeist. Lo único que se puede definir colectivamente son las condiciones (políticas, económicas, religiosas, nacionales, lingüísticas, etc.) que influyen sobre las experiencias individuales que luego son recogidas en textos, museos, monumentos o cualquier otra superficie de inscripción. Para Koselleck, la colectivización del recuerdo, el hecho de que se convierta en algo común a toda una comunidad, es fruto de la ideología política. En su opinión, la política, aunque influye sobre la historia, no debe imponer sus fines ${ }^{27}$. En caso contrario, si se politiza la historia, caemos en la ideología y nos apartamos de la verdad.

Koselleck subraya el carácter intransferible de toda experiencia primaria. A este respecto menciona sus propios recuerdos de la Segunda Guerra Mundial; recuerdos, cuya sensación de verdad o «certeza sensible» hace mucho tiempo que se ha desvanecido. Para él, tales recuerdos no son más que «historias literarias» de carácter subjetivo ${ }^{28}$, y se refieren a

25. Sobre este tema, cabe destacar, entre otros, los textos de F. Oncina "El giro icónico en la memoria: el caso de Reinhart Koselleck", en F. Oncina y M. E. Cantarino, Estética de la memoria, Valencia, 2011, 123 150, y "Koselleck y el giro icónico de la historia conceptual", Anthropos, 223, 2010, 43-85. Y el artículo de D. Fusaro, "Reinhart Koselleck y los monumentos como indicadores de los cambios históricos y políticos", Historia y Grafía, 45, 2015, 95-122.

26. F. Hartog, Régimes d'historicité. Présentisme et expériences du temps, París, 2012, 167.

27. R. Koselleck, "I monumenti: materia per una memoria collettiva?", Discipline filosofiche, 2, 2003, 9-10.

28. Koselleck señala en una entrevista que "la ola de memorialismo [...] supone una abdicación de la historia objetiva en favor de la historia subjetiva, según el sentido tradicional de estos dos adjetivos. Si se insiste en la memoria se está diciendo que la historia subjetiva es mucho más importante que el análisis ob- 
«experiencias que no son intercambiables ni comunicables» ${ }^{29}$. Esta tesis, fundada en la radical separación entre la memoria primaria individual, que el historiador menosprecia como simple literatura por narrar experiencias incomunicables, y la historia objetiva, cuyo saber sí es universalmente transmisible, resulta muy discutible porque implica de alguna manera rechazar los testimonios de actores y testigos. Para Koselleck, la historia no tendría nada que hacer con obras literarias como las de Levi, Améry, Cayrol, Solzhenitsyn y tantos otros que se refieren al universo concentracionario, y a filmes como los de Claude Lanzmann, Rithy Panh o Patricio Guzmán, construidos a partir de las experiencias y testimonios de víctimas y verdugos. Todas estas obras de arte demuestran, por lo demás, que en la memoria convergen las preocupaciones estéticas y las históricas.

Para deshacer los errores que denuncia Koselleck, convendría distinguir entre la memoria del abstracto «sujeto colectivo» y la concreta «memoria histórica» basada en los recuerdos de los actores y testigos singulares. En el fondo, la historia siempre se ha servido de estas vivencias primarias. No es menos cierto que hay un inevitable componente político, valorativo y subjetivo en la memoria histórica, pero esto, como expresa el pensamiento del punto de vista o de la unilateralidad, no es un defecto. Por lo demás, la democratización creciente de nuestras sociedades fomenta el deber individual de memoria, el hecho de que cada uno pueda convertirse en historiador de sí mismo. A este respecto, Pierre Nora contrapone, aun con cierto disgusto, los tiempos actuales al pasado de las «sociétés-mémoires» ${ }^{30}$, en el que solo había tres grandes productores de archivos: las grandes familias, la Iglesia y el Estado. En la actualidad, la mayoría de los historiadores de la época contemporánea admiten los testimonios, pero solo como «fuentes orales» que, a semejanza de las escritas, necesitan pasar antes por el filtro del intermediario, del historiador, para que puedan expresar la verdad histórica ${ }^{31}$.

También convendría distinguir entre la memoria positiva y la negativa. La primera es, en la mayoría de los casos, pura ideología nacionalista porque hace referencia a hechos del pasado que reafirman la identidad de una comunidad política. Esta memoria nacional o estatal es un concepto tan abstracto como el resto de conceptos de la modernidad, empezando por el de soberanía. Pero Koselleck también reconoce la existencia de una memoria negativa que hace referencia a hechos traumáticos y, desde luego, al sinsentido de la guerra. Esta memoria histórica negativa o traumática supone un desmontaje, a partir del recuerdo singular de infinidad de hombres y mujeres, de aquella otra memoria afirmativa. Por esta razón sigue teniendo una indudable función terapéutica, que es al mismo tiempo ética y política. Frente al cierto desprecio

jetivo de los historiadores, y eso es un disparate. [...] El auténtico análisis del pasado histórico requiere una aproximación teórica que va más allá de las vivencias subjetivas, de los recuerdos de esos acontecimientos reales que, sin duda, se reorganizan luego ideológicamente." (J. F. Fuentes y J. Fernández Sebastián, “Historia conceptual, memoria e identidad (I). Entrevista a Reinhart Koselleck", Revista de libros, 112, 2006, 19-22).

29. "Glühende Lava, zur Erinnerung geronnen. Vielerlei Abschied vom Krieg: Erfahrungen, die nicht austauschbar sind», Frankfurter Allgemeine Zeitung, 6-V-1995. Cfr. F. Oncina, "Necrológica del Outsider Reinhart Koselleck: el «historiador pensante» y las polémicas de los historiadores”, Isegoría, 37, $2007,53$.

30. F. Hartog, Régimes d'historicité..., op. cit., 171.

31. F. Hartog, Évidence de l'histoire. Ce que voient les historiens, París, 2007, 262 
que manifiesta Koselleck hacia la memoria como simple literatura, los artistas han demostrado la estrecha relación que existe entre la superación de la crisis existencial, gracias a la memoria individual del trauma ocasionado por una guerra o un genocidio, y la superación de la crisis existencial colectiva de una nación o de cualquier comunidad humana mediante la inscripción histórica de los sucesos traumáticos. Precisamente, lo que un artista puede hacer mejor que nadie, mejor incluso que un historiador o un filósofo, es ofrecer un punto de vista individualizado. Frente al crimen colectivo expresado en cifras, los artistas suelen volver la mirada a lo más singular. Es decir, ponen nombres y rostros a las víctimas, y dan la palabra al testigo para que transmita a las generaciones posteriores su experiencia.

Sin duda, el tema de la memoria, por estar ligado a vivencias personales, ocupa más a los artistas que a los historiadores, aunque la memoria de nuestros días es, como suele decir Hartog, encuestadora, archivística e historiadora. Koselleck, en lugar de analizar las manifestaciones literarias y audiovisuales que en nuestro tiempo proporcionan las obras más reseñables de memoria histórica, se centra en los seculares monumentos o memoriales públicos dedicados a las víctimas caídas en conflictos bélicos. El historiador de los conceptos reconoce que estos monumentos «tienen un excedente potencial de significados que elude los fines con los que fueron erigidos» ${ }^{32}$. De ahí que, si no atendemos a las inscripciones y a otros signos empíricos, no se pueda saber a menudo su significación primera. Tales monumentos son para este autor un ejemplo de «memoria colectiva» o, para ser más exactos, de política de la memoria, pues suelen tener una determinada función política. $\mathrm{O}$ al menos, así ha sucedido hasta la Segunda Guerra Mundial.

Antes de la Revolución francesa, la representación de la muerte aparecía en los monumentos funerarios como un pasaje al más allá y difería según los órdenes sociales ${ }^{33}$. Tras la entrada en la modernidad, el monumento dedicado a los muertos en un conflicto bélico posee, con independencia de las diferencias nacionales ${ }^{34}$, dos propiedades esenciales: tiene una función política porque concierne sobre todo a los supervivientes; y posee un carácter democrático porque cualquiera tiene derecho a figurar en el monumento.

En relación con la función política, debemos señalar que, desde la Revolución francesa hasta la Segunda Guerra Mundial, los monumentos dan una respuesta común a la pregunta por el significado de la muerte en la guerra, del «morir por...». Koselleck no se equivoca cuando señala que tales monumentos aúnan «en un horizonte de significado común el pasa-

32. Véase el capítulo "Les monuments aux mort, lieux de fondation de l'dentité des survivants" de R. Koselleck, L'expérience de l'histoire, París, 1997, 158.

33. R. Koselleck, Lexpérience..., op. cit., 138.

34. Es cierto que también Koselleck ha estudiado las diferencias que acerca del culto de la muerte y elaboración de monumentos se puede apreciar entre los diversos países, especialmente entre Francia y Alemania. Koselleck (Los estratos..., op. cit., 150-153) señala así que, en el primero de estos países y no en el segundo, adquiere una gran importancia los monumentos municipales “erigidos en señal de duelo", siempre con el fin de "mantener vivo el duelo por los muertos como garantía de la paz"; se rechaza, en sintonía con el laicismo de la nación francesa, "la participación de las Iglesias en el cuidado de la memoria"; o se establece después de 1945, por orden del general De Gaulle, que solo se levanten "nuevos monumentos para la Resistencia". 
do de la muerte con el futuro de los supervivientes» ${ }^{35}$. Los monumentos se ponen al servicio de la fundación y conservación de los Estados nacionales. En cierto modo, el lugar escatológico del más allá lo ocupa la promesa de un futuro esplendoroso para la nación. Lo importante es que se muere en la guerra para que los supervivientes tengan un venturoso porvenir.

Koselleck analiza asimismo cómo, a partir de la Revolución francesa, tiene lugar una democratización de la memoria de los caídos. En los memoriales de guerra se empieza a consignar todos los nombres de los soldados muertos con independencia del grado militar. Uno de los últimos y más relevantes ejemplos, lo encontramos en el Vietnam Memorial de Washington realizado por Maya Lin, el cual recoge el nombre de todos los soldados norteamericanos caídos en Vietnam. El hecho de que se haya excluido de estos memoriales a los enemigos es la otra cara de una tendencia democratizadora que acaba poniéndose al servicio de la ideología nacionalista. Contra esta exclusión, Chris Burden decidió parodiar el memorial de Maya Lin con la elaboración de un monumento, The other Vietnam Memorial, que está dedicado a los muertos vietnamitas que fueron ignorados por la memoria norteamericana $^{36}$. Koselleck recuerda a este respecto que, poco antes de la Primera Guerra Mundial, en el momento en que el nacionalismo alcanza su madurez y se transforma en imperialismo, llega a su máxima expresión el antagonismo entre Estados que luchan por la hegemonía. En este contexto se acaba criminalizando al enemigo, el cual ya no puede ser recordado en los monumentos que el Estado-nación levanta en homenaje a sus soldados fallecidos. En cambio, durante el siglo XVIII y buena parte del XIX, se consideraba normal que no se excluyera a los enemigos de estos memoriales. Una buena muestra era la capilla del Garnison-Friedhof de Berlín, que recordaba a los combatientes prusianos y franceses de los años 1813-1815.

En contraste con la tendencia democrática que poseen los monumentos modernos, en la sociedad jerarquizada del Antiguo Régimen «los nombres de los soldados muy rara vez, por no decir nunca, se consideraban dignos de ser recordados» ${ }^{37}$. En aquella época solo se recordaba a los generales, aristócratas o a los hombres excepcionales en los monumentos o en las pinturas pertenecientes al género histórico. Este tránsito desde el Antiguo Régimen a los Estados modernos se apreciaba claramente en la figura de San Jorge, uno de los principales emblemas europeos del héroe en lucha contra el mal. Después de la Primera Guerra Mundial, el santo podía llegar a ser encarnado, en esculturas y monumentos funerarios, por un simple soldado raso $^{38}$. La última etapa de este proceso de democratización de la muerte tiene lugar con la aparición de las tumbas y monumentos dedicados al soldado desconocido, o, como también lo llama Koselleck, al «muerto simbólico» ${ }^{39}$. Su aparición se debía a que la técnica de la guerra moderna hacía imposible en muchos casos la identificación de los muertos. En la

35. R. Koselleck, Los estratos..., op. cit., 146.

36. R. Koselleck, “I monumenti...”, op. cit., 20-21.

37. R. Koselleck, L’expérience..., op. cit., 151.

38. R. Koselleck, “I monumenti..., op. cit., 13.

39. R. Koselleck, Los estratos..., op. cit., 148. 
tumba dedicada al soldado desconocido, el nombre pasaba a segundo plano, pues se recordaba ante todo la causa por la cual fue sacrificado.

Koselleck ha mostrado en sus escritos que todos los monumentos son portadores de un sentido, lo cual no significa que lo tengan los mismos acontecimientos recordados en estas obras. Lo que domina en los monumentos actuales es el mensaje de la absoluta falta de sentido, del absurdo, que supone morir en una guerra ${ }^{40}$. Hasta la Segunda Guerra Mundial, los monumentos no aludían realmente al fenómeno de la muerte, sino a la función política que desempeñaba la muerte de una masa de soldados. Después de Auschwitz, del Gulag y de las bombas atómicas, se tiende a evocar la muerte en sí misma, en lugar de cargarla de la significación suplementaria que implica ponerla al servicio de la mitología nacional ${ }^{41}$. En este nuevo contexto, los enterramientos colectivos y los monumentos a los caídos dejan de transmitir valores patrióticos y de ensalzar la gloria nacional. La muerte en la guerra ya no tiene la función política de consolidar o conservar el Estado nación. En los nuevos monumentos -escribe Koselleck- «se hace patente que la muerte ya no se entiende como una respuesta, sino solo como una pregunta, no como algo que confiere sentido, sino como algo que requiere un sentido». Está claro que, cuando "ya no es posible presuponer, encontrar o rastrear el sentido», solo cabe expresar el carácter absurdo e inefable de lo acontecido ${ }^{42}$.

A pesar de que la memoria histórica de las guerras mundiales se ha plasmado en muy diversas disciplinas artísticas, Koselleck solo ha estudiado los monumentos o memoriales realizados por artistas tan relevantes como Käthe Kollwitz, Edward Kienholz, Françoise Salmon, Ossip Zadkine, Christian Klepsch, Conrado Casti, Daniel Libeskind o Jochen Gerz. De todos ellos, Koselleck destaca el arte de Käthe Kollwitz, pues, en su opinión, es la autora de un «monumento estéticamente insuperable, que visualiza la inútil búsqueda de un sentido a la muerte violenta $»^{43}$. Después de que transcurrieran casi veinte años desde la muerte en 1914 de su hijo, la artista alemana decidió crear un conjunto escultórico, Trauernde Eltern, para el cementerio donde estaba enterrado su hijo. Esta obra tematizaba la muerte en sí misma, y no «el morir por» algo ${ }^{44}$. En lugar de mostrar al soldado muerto, cuya ausencia definitiva no puede compensarse con ninguna imagen, Kollwitz se limitaba a mostrar en sus esculturas el dolor y el duelo de los padres supervivientes.

No nos parece tan acertado lo que Koselleck dice a continuación acerca de otra obra de esta artista. Más allá de que sea discutible, desde el punto de vista estético, la operación póstuma de convertir en 1993 la Pietà de Käthe Kollwitz, una pequeña escultura creada en 1937-38, en un monumento para la Neue Wache de Berlín, bajo el cual están enterrados los restos de un soldado desconocido y de un prisionero desconocido de un campo de concentración, no nos parece, sin embargo, acertada la crítica que Koselleck formula contra este motivo temático. En

\footnotetext{
40. R. Koselleck, “I monumenti..., op. cit., 24.

41. R. Koselleck, L’expérience..., op. cit., 145.

42. R. Koselleck, Los estratos..., op. cit., 147.

43. R. Koselleck, "I monumenti...", op. cit., 27.

44. R. Koselleck, L'expérience..., op. cit., 149.
} 
su opinión, la utilización de la iconografía cristiana de la Pietà en monumentos creados después de la Segunda Guerra Mundial, da lugar a obras artísticas y públicas de notable mal gusto, ya que resulta inevitable que la Piedad, por su relación con el deicidio de Cristo, se convierta en un gesto antisemita ${ }^{45}$. Es sorprendente esta interpretación, sobre todo si tenemos en cuenta que la Pietà, un episodio ausente en los Evangelios y problemático para el cristianismo, constituye el motivo iconográfico en el que está más presente la mortalidad del cuerpo de Cristo, la kénosis o ausencia de divinidad ${ }^{46}$. El Hijo aparece en el mito cristiano como la imagen del Padre. Solo en su muerte se convierte en imagen de la madre; es decir, solo en la Pietà, que alude, como si fuera una natividad invertida, al retorno de un cuerpo a ese otro cuerpo al que le debe su mortalidad, el Hijo se parece a la madre. Se trata, por tanto, de un motivo iconográfico que, lejos de acusar a los judíos, expresa con crudeza y ternura la muerte del hijo.

El pensamiento de Koselleck sobre las instituciones alemanas que levantan monumentos o memoriales a las víctimas del Tercer Reich, no está exento de aspectos cuestionables. Para el historiador de los conceptos, tales instituciones no deberían privilegiar a los judíos sobre los homosexuales, gitanos, enfermos mentales, polacos, soviéticos, prisioneros de guerra, etc.: «no podemos incluir -escribe a este respecto- ni excluir a grupos concretos de víctimas. No podemos fijar las fronteras arbitrarias de los grupos que fueron destinados a la muerte, estableciendo una jerarquía de las víctimas» ${ }^{47}$. Koselleck sostiene que, con esta jerarquización de las víctimas, no solo las nuevas instituciones alemanas están aceptando las categorías con las que las SS y la Wehrmacht clasificaban a los grupos humanos perseguidos y exterminados, sino que, además, están incumpliendo el imperativo ético de dedicar monumentos o memoriales a todos los seres humanos que han sido víctimas del poder totalitario ${ }^{48}$.

Es cierto que no se debe establecer una jerarquía entre las víctimas, pero tampoco parece que la solución sea elaborar monumentos que les rindan un homenaje genérico, pues ello supone incurrir en esa memoria pública abstracta que el propio Koselleck critica en otras ocasiones. Lejos de aceptar las categorías nazis, al hacer memoriales en los que se singulariza el nombre de los grupos que sufrieron el exterminio, realizamos un gesto opuesto al del verdugo que desearía la desaparición de todos esos nombres singulares, y, desde luego, la del nombre judío. Quien ha llegado más lejos en la oposición a englobar todas las víctimas bajo el mismo nombre es Jean-Claude Milner. Seguramente, este pensador francés vería en la propuesta de Koselleck un ejemplo de ese «universal fácil» o todo ilimitado -notodo, en palabras de Lacan- que fue inventado por Pablo de Tarso en Gálatas 3, 28. Milner sostiene que el universal fácil está unido necesariamente a la «conversión», es decir, a la sustitución de los distintos nombres que indican todos limitados, empezando por el de judío, por el nombre

45. R. Koselleck, “I monumenti..., op. cit., 28.

46. M.-J. Mondzain, Homo spectator, Montrouge, 2013, 202 ss.

47. R. Koselleck, Modernidad, culto a la muerte y memoria nacional, Madrid, 2012, 51.

48. R. Koselleck, “I monumenti..., op. cit., 33. 
del cualquiera y por el todo ilimitado ${ }^{49}$. Desde este enfoque, los memoriales genéricos o abstractos dedicados a la humanidad sufriente constituyen una forma de tachar el nombre judío y, por tanto, de agravar los efectos de la Shoah.

Koselleck vuelve a equivocarse cuando escribe que no incumbe a los alemanes «erigir monumentos a las víctimas, como les correspondería a estas». Sorprende que no tenga en cuenta que muchas de estas víctimas fueron alemanas, más allá de que el Tercer Reich les arrebatara a todas ellas los derechos políticos y civiles. El historiador agrega que los alemanes deben, por el contrario, «erigir un monumento de los verdugos, por difícil que esto sea. Un monumento de los verdugos que nos recuerde quién tiene la responsabilidad de los asesinatos, el exterminio y el gaseado. Tratemos de aprender a vivir con ese recuerdo ${ }^{50}$. Esta distinción entre monumentos dedicados a las víctimas y a los verdugos también resulta sorprendente, pues, como demuestran los ejercicios de memoria histórica que se han hecho desde el cine (Resnais, Lanzmann, Farocki, Rithy Panh, etc.), ambas cosas, el homenaje a la víctima y la condena del verdugo, resultan inseparables.

Koselleck reconoce en cierto modo que, después de 1945, los mejores monumentos dedicados a los caídos son los que tematizan el duelo. Tras la Segunda Guerra Mundial se produce una creciente relación entre el trabajo del duelo y el trabajo de la memoria histórica que lleva a inscribir los hechos del pasado en el museo, en libros, en obras de arte, etc. Ya no se trata -como el mismo Koselleck reconoce- de dotar de significado político a la muerte en la guerra, sino más bien de «olvidar» el dolor por medio del recuerdo, como expresa la tesis de Jean-Louis Déotte sobre el «olvido activo $»^{51}$. Para que pueda «pasar el pasado» y se abra el horizonte de un futuro, para que los seres humanos vuelvan a recuperar la energía y puedan tener un mañana, es necesaria la operación terapéutica de la memoria. La inscripción de los acontecimientos traumáticos, luctuosos, en un relato histórico, en un museo o en una obra de arte, permite abrir una sana distancia con respecto a ese pathos o masa amorfa de sentimientos dolorosos que inmoviliza al sujeto en un eterno y doloroso presente. Esta inmovilización tiene mucho que ver con la última categoría que vamos a abordar.

El historiador de los conceptos también se preocupa por la fragilidad de la memoria inscrita en los monumentos, pues no siempre es capaz de sobrevivir a "la generación de los supervivientes». Koselleck repara así en el peligro de extinción del culto a los muertos, es decir, llama la atención sobre el peligro de que los monumentos se limiten a dar «testimonio del pasado»y «ya no apunten al futuro» ${ }^{52}$. El pasado deja entonces de ser memoria «viva»y cae en el olvido o en la indiferencia, pues «las experiencias o los mensajes políticos son difícilmente transmisibles más allá» de la generación de los supervivientes ${ }^{53}$. La petrificación del

49. Sobre ello trata J.-C. Milner en Las inclinaciones criminales de la Europa democrática, Buenos Aires, 2007, 37-38, y en El judío del saber, Buenos Aires, 2008, 77-82.

50. R. Koselleck, Modernidad..., op. cit., 51.

51. J.-L. Déotte, Oubliez! Les ruines, l'Europe, le musée, París, 1994, 19.

52. R. Koselleck, Los estratos..., op. cit., 149.

53. R. Koselleck, L'expérience..., op. cit., 159. 
recuerdo en objetos cuya contemplación acaba por ser indiferente para las nuevas generaciones es un mal inherente a los monumentos, así como al conjunto de objetos pertenecientes al pasado que se depositan en un archivo o en un museo. Koselleck estaba convencido de que esta patología se podía combatir con el trabajo de las «instituciones sociales», esto es, con el trabajo que se realizaba desde las escuelas, los museos, las cámaras de representantes políticos, etc. El Benjamin de los Pasajes nos enseñó que, en realidad, este mal solo se puede evitar si el pasado continúa siendo memoria viva, si está unido a los problemas del presente, pues los hechos pretéritos se olvidan enseguida cuando permanecen aislados de la experiencia contemporánea. En opinión del judío alemán, «toda imagen del pasado que no sea reconocida por el presente como uno de sus motivos de preocupación» corre el riesgo de desapare$c \mathrm{r}^{54}$. De ahí que, con respecto a la política de la memoria, sea necesario subrayar la relación que existe entre la violencia o abusos del pasado y las patologías que hoy nos preocupan.

\section{La Stimmung de latencia y el «presentismo» contemporáneo: el fin de los tiempos modernos}

Abordamos en este apartado el pensamiento de Gumbrecht sobre la latencia ${ }^{55}$, que sobre todo ha desarrollado en su libro Después de 1945. La latencia como origen del presente. Pertenece este libro a un proyecto intelectual, que podemos expresar con los términos «ontología de la presencia», que, en contraste con la preponderancia moderna adquirida por la hermenéutica o la cultura de la significación, se esfuerza por recuperar la importancia de los efectos de presencia en sus diversas manifestaciones. Tales efectos son especialmente visibles en la singular experiencia o vivencia estética, tan importante, por lo demás, para un pensador que se ha destacado sobre todo en el campo de los estudios literarios. Pero también esos efectos de presencia son decisivos en la historia.

Para empezar, cabría preguntarse cuánto debe el pensamiento de Gumbrecht a Koselleck, y, en particular, a la polémica mantenida por el autor de Futuro pasado con la hermenéutica de Gadamer. La latencia es una de esas categorías que, como la Stimmung ${ }^{56}$, escapan a la interpretación lingüística y, por ello, pertenecen a la denominada ontología o cultura de la presencia. La distinción que establece Gumbrecht entre el paradigma de la significación y el de la presencia ${ }^{57}$ está relacionada con la diferencia entre la comprensión de los textos centrada en la interpre-

54. Véase D. Frisby, Fragmentos de la modernidad. Teorías de la modernidad en la obra de Simmel, Kracauer y Benjamin, Madrid, 1992, 394.

55. Un análisis de la latencia, a partir de "los trabajos de Husserl acerca de la constitución originaria de la temporalidad”, se puede encontrar en el artículo de J. L. Villacañas, "Latencia. La elaboración de la experiencia originaria”, Diánoia, 76, 2016, 3-28.

56. Sobre esta categoría de Stimmung, véase el libro de H. U. Gumbrecht, Stimmungen/Estados de ánimo. Sobre una ontología de la literatura, Murcia, 2011.

57. H. U. Gumbrecht, Production of Presence. What meaning cannot convey, Stanford, 2004. 
tación y la indagación que busca lo que los textos revelan involuntariamente. Hay, por tanto, cosas relacionadas con el discurso histórico que escapan a la interpretación lingüística.

Koselleck ha subrayado, frente a Gadamer, la importancia de esas categorías extralingüísticas, que ha englobado con el término de Historik, para explicar cualquier historia, empezando por la conceptual. La Histórica reúne los pares opuestos o antitéticos de «tener que morir» $\mathrm{y}$ «poder matar», «amigo» $\mathrm{y}$ «enemigo», «interior» $\mathrm{y}$ «exterior», la categoría de la generatividad o Natalität, esto es, la diferencia entre una generación y la siguiente, y la del «amo» y «esclavo» o dominador y dominado ${ }^{58}$. En la entrevista con Dutt reducía los cinco pares anteriores a los dualismos fuera-dentro, antes-después y arriba-abajo, eliminando las categorías más influenciadas por Heidegger y Schmitt ${ }^{59}$. Gumbrecht también se aparta de la hermenéutica cuando utiliza categorías «ahistóricas» parecidas a las de Koselleck. En concreto, se refiere, como comentaremos enseguida, a tres configuraciones o medios extralingüísticos para expresar la Stimmung de latencia, es decir, para «mantener cubierto y alejado lo latente».

La atmósfera o estado de ánimo de latencia domina, a juicio de Gumbrecht, en la época postmoderna que se caracteriza por el estancamiento del tiempo o por la detención del movimiento histórico. En estas circunstancias resulta inevitable la neutralización de los tres pares antitéticos mencionados por Koselleck. El hecho de que el anacronismo deje de ser una preocupación supone un síntoma del fin del tiempo moderno, el cual estaba marcado por la expectativa de progreso, por caminar hacia un futuro emancipador que deja definitivamente atrás las instituciones del pasado, y por el carácter «futuro-céntrico» de los conceptos. Ahora bien, este final de la modernidad tampoco supone una vuelta al mundo premoderno, el cual se caracterizaba por el mayor peso de la experiencia, de las tradiciones, y por la dimensión «pasado-céntrica» de los conceptos ${ }^{60}$. La yuxtaposición en el presente de temporalidades diferentes se traduce en la suspensión de la tensión entre el antes y el después o entre las distintas generaciones. De forma similar, la memoria contemporánea anula la diferencia entre arriba-abajo, pues la democratización de la memoria ya ni siquiera depende de la relación vertical de servicio a conceptos abstractos y modernos como el de nación y pueblo soberanos, o a conceptos tradicionales, y sociológicamente reales, como los de familia e Iglesia. Aparecen entonces manifestaciones históricas horizontales que se corresponden con un «ni arriba ni abajo». Finalmente, la Stimmung de latencia hace referencia a un «ni fuera ni dentro», a un tiempo sin acontecimientos positivos que nos sitúen ante la experiencia de estar en el mundo como en casa o de que las cosas se hallan en el lugar que les corresponde.

Gumbrecht se refiere a tres configuraciones de los topoi, o de las situaciones en las que nos vemos envueltos, que expresan «resultados o reacciones a la situación de latencia». De estas tres configuraciones, la más importante se resume en la expresión «no salir, no entrar»,

58. R. Koselleck y H.-G. Gadamer, Historia y hermenéutica, Barcelona, 1997, 73-85.

59. Autor/a, "Historia(s) e Histórica. Reinhart Koselleck en conversación con Carsten Dutt”, Isegoría, 29, 2003,212

60. D. Fusaro, "Il tempo dei concetti. La riflessione filosofica di Reinhart Koselleck", Giornale Critico di Storia delle Idee, 8, 2012, 75. 
que, si la relacionamos con las categorías ahistóricas de Koselleck, se podría traducir con los términos de «ni fuera ni dentro». Se trata, en realidad, del deseo frustrado de traspasar umbrales, pues dicha configuración «combina el sentimiento claustrofóbico de encierro en un espacio sin salida, con la opuesta, si bien complementaria, obsesión de estar en el exterior, sin poder acceder a un espacio interior, que aparece cerrado, sin puertas, sin entradas ${ }^{61}$. Gumbrecht se sirve de la estética, de la reflexión sobre el arte, para pensar, en general, la historia y, en particular, la crisis del cronotopo moderno tal como se expresa a través de la Stimmung de latencia. Por eso menciona como ejemplos de espacio sin salida la obra teatral de Sartre Huis clos, El ángel exterminador del cineasta Buñuel y Esperando a Godot, aunque también podría haber aludido a otra obra de Beckett, tan relevante para expresar el confinamiento, como Fin de partida. La experiencia contraria, la de no poder entrar en un espacio deseado, es expresada de modo ejemplar por el drama, hoy casi olvidado, de Wolfgang Borchert, Afuera, frente a la puerta (Draussen vor der Tür), que fue estrenado en 1947. El protagonista de este drama, el soldado Beckmann, intenta acceder a la sociedad que surge tras el fin de la guerra, "pero solo encuentra puertas cerradas, rechazo y falta de ayuda ${ }^{62}$. Desde luego, esta frustrada experiencia, la de no poder cruzar el umbral que lleva al lugar querido, ya fue expuesta de modo magistral por los relatos y novelas de Kafka en el periodo de entreguerras. Lo importante para Gumbrecht es que todas estas vivencias decepcionantes se corresponden con la Stimmung de la latencia, con la experiencia de que no podemos salir del presente ni podemos entrar en el futuro porque lo latente no se desvela.

Las otras dos configuraciones son resumidas con las palabras «mala fe y preguntas» $\mathrm{y}$ «descarrilamientos y recipientes». La primera hace referencia a la falta de transparencia, a la «imposibilidad de sacar a luz verdades escondidas o latentes», o a la existencia de dimensiones del ser humano que, como la sexualidad, permanecen opacas a pesar de todos los esfuerzos realizados por las ciencias. Y la segunda configuración se refiere al estado existencial de vacío, desilusión o descarrilamiento que "subyace a la obsesión de ser contenido y protegido» ${ }^{63}$, de hallar la calma, sin conseguirlo, «dentro de un espacio estrecho y bien definido», esto es, dentro de un recipiente o contenedor ${ }^{64}$. En realidad, los topoi que aluden a la opacidad o falta de transparencia y a la sensación de vivir en la intemperie también constituyen una forma de anular la diferencia y tensión entre fuera-dentro, exterior-interior, que tan relevante ha sido para describir el movimiento de la historia. Por un lado, la verdad latente puede ser concebida en unas ocasiones como un afuera al que no se puede acceder y en otras como un interior al que no se puede penetrar. Por otro lado, la obsesión por el contenedor se debe a que, en la situación de desamparo en que vive el hombre postmoderno, ya no se puede tener una vivencia en la que se distinga entre el interior y el exterior. Aunque Gumbrecht no se sirve del pensamiento político de Foucault y Deleuze, algo parecido sucede con la «sociedad de

61. H. U. Gumbrecht, Después de 1945. La latencia como origen del presente, México, 2015, 38.

62. H. U. Gumbrecht, Después de 1945..., op. cit., 39.

63. H. U. Gumbrecht, Después de 1945..., op. cit., 198.

64. H. U. Gumbrecht, Después de 1945..., op. cit., 40. 
control» contemporánea que ha dejado obsoleta la diferencia entre el dentro y el afuera que caracterizaba a la foucaultiana «sociedad disciplinaria». En cualquier caso, las dos configuraciones mencionadas hacen referencia a la promesa incumplida de la modernidad, a un futuro que no termina de llegar, y a una situación en la que ni se desvela la verdad, ni se sitúa cada cosa en su lugar, ni es posible encontrar un espacio de protección. Gumbrecht concluye que «nos hemos quedado solamente con deseos irredentos, incertidumbres y desorientación», o incluso con la sensación de que «un futuro que nunca elegimos nos amenaza» ${ }^{65}$.

El autor de Después de 1945 se niega a identificar esta categoría, la latencia, que escapa a la hermenéutica y que pertenece a la cultura de la presencia, con la freudiana represión ${ }^{66}$ o con el olvido. Se trata de "presencia en ausencia», de algo que sabemos que está ahí, pero que no ha emergido, que no se ha hecho visible, y por ello no podemos saber qué es. Para describirlo, Gumbrecht utiliza incluso la metáfora del polizón. Sostiene este autor que su generación «ha experimentado su tiempo con la expectativa y la esperanza [...] de que algo latente se manifestaría y revelaría ${ }^{67}$. Está claro que la latencia tiene que ver con un universo en tensión, esto es, con la esperanzada expectativa de que finalmente lo latente se desvelará, y con la confianza de que ello produzca un efecto de redención. Pero todo esto no hace más que reflejar la estructura temporal «futurocéntrica» de la modernidad, en la que predomina la expectativa sobre la experiencia. Recordemos que Koselleck es quien más ha subrayado la importancia de este par de categorías, experiencia y expectativa ${ }^{68}$, para pensar la diferencia entre lo premoderno y lo moderno.

El problema es que la promesa moderna de redención no se ha cumplido. Gumbrecht escribe a este respecto que «nuestra situación es como la de Vladimir en la obra de Beckett: "Bueno, supongo que al final me levantaré por mí mismo. (Lo intenta, fracasa). Cuando los tiempos se cumplan". Nosotros podemos aún esperar que este "cumplimiento del tiempo" llegue, pero al mismo tiempo no creemos que tal cosa ocurrirá ${ }^{69}$. Esperando a Godot se convierte así en la gran referencia literaria de la pérdida contemporánea de fe en el desvelamiento de lo latente. Según Gumbrecht, el mundo de la obra de Beckett es el de la inmovilidad, el del tiempo congelado: se espera indefinidamente, sin que nunca llegue aquello que permite el cambio, el movimiento. El latente Godot obliga a Vladimir y Estragón, a Didi y Gogo, a permanecer donde están, siempre a la espera. Lo latente «congela» el tiempo: «el tiempo congelado -añade Gumbrecht ${ }^{70}$ - hace que todo progreso, y por ende, toda acción de cualquier tipo, sea imposible, puesto que las acciones necesitan del futuro para transformarse de motivaciones en realidad». El tiempo congelado es el tiempo sin duelo, el de las estatuas

65. H. U. Gumbrecht, Después de 1945..., op. cit., 41.

66. H. U. Gumbrecht, Después de 1945..., op. cit., 153.

67. H. U. Gumbrecht, Después de 1945..., op. cit., 31.

68. Véase el capítulo “"Espacio de experiencia» y «Horizonte de expectativa», dos categorías históricas” de R. Koselleck, Futuro pasado..., op. cit., 333-357.

69. H. U. Gumbrecht, Después de 1945..., op. cit., 31.

70. Todas las citas de estos dos párrafos corresponden a H. U. Gumbrecht, Después de 1945..., 29-31. 
petrificadas que, en L’Anéee dernière à Marienbad (1961) de Resnais, simbolizan el presente eterno del que no pueden escapar sus espectrales protagonistas.

El mundo detenido o el presente ancho, al que se refiere Gumbrecht, y que coincide en parte con el más complejo "presentismo» teorizado por François Hartog ${ }^{71}$, encuentra, por tanto, en Esperando a Godot su mejor plasmación. Para los personajes de este drama nunca llega lo que está latente. La interpretación que hace Robbe-Grillet de las obras del autor irlandés coincide en gran medida con la de Gumbrecht. A juicio del francés, Fin de partida muestra que "todo lo que "es"» está en el escenario: fuera no hay nada, solamente el no-ser. Así lo expresa el personaje Clov cuando mira por las dos ventanas del escenario: «un mar vacío y gris por un lado, y una tierra desierta por otro». Y Hamm repite: «fuera de aquí solo existe la muerte». La concentración «aquí» de todos los espacios y «ahora» de todos los tiempos, tiene como resultado una obra en la que, al no existir ni pasado ni futuro, impera el encierro y la inmovilidad, y en la «que toda idea de progreso o dirección, todo significado, se excluye» ${ }^{72}$. Para Ernesto de Martino, este mundo detenido se corresponde con el de la crisis de la presencia. La obra de Beckett es así la encarnación literaria del apocalipsis cultural, de la pérdida de energía necesaria para que nuestra cultura pueda afrontar con resolución, con proyectos que motiven y con valores intersubjetivos, las situaciones críticas y de riesgo ${ }^{73}$. Mientras dura el estado de crisis cultural, los hombres permanecen detenidos en un presente que cada vez se hace más amplio, pues se trata de un presente sin pasado, sin que nada quede atrás, y sin futuro, sin proyecto. La Stimmung de latencia y el presente ampliado son, por tanto, propios de una época de crisis existencial e incluso de apocalipsis cultural ${ }^{74}$.

La aparición de un tiempo sin resolución o redención, que, a juicio de Gumbrecht, se impone después de 1945, implica el fin de la noción moderna de tiempo histórico, del cronotopo de la modernidad. Basándose en los escritos de Koselleck, sostiene que este cronotopo cumplía tres condiciones: «dejar atrás el pasado, ir a través de un presente como

71. Mientras que la sensación de frustración y decepción domina cuando pensamos en el ancho y lento presente de Gumbrecht, Hartog (Régimes d'historicité..., op. cit., 150-156) no solo se refiere a un "presentismo» "pesant et désespéré" como el de esos hombres sin futuro que son los parados, sino también a una versión optimista. Esta versión la encontramos en el "presente futurizado» de experiencias históricas exitosas como el «Milagro» alemán o los «Trente Glorieuses» franceses, en la creciente valorización de la juventud, en el slogan "oublier le futur" de los Sixties, etc. En la introducción añadida en 2012, titulada "Présentisme plein ou par défaut?", Hartog (Régimes d'historicité..., op. cit., 17) señala que el "présent présentiste” de nuestros días se vive de forma muy diferente según sea la posición social que se ocupa: bien como horizonte abierto si se está del lado de los privilegiados, bien como horizonte cerrado si se está dentro del "précariat".

72. A. Robbe-Grillet, "Samuel Beckett, o la presencia en el teatro", Casa del tiempo, 87, 2006, 83.

73. E. de Martino, La fine del mondo. Contributo all'analisi delle apocalissi culturali, Turín, 2002, 551-552.

74. El aburrimiento, la noia de Moravia (E. de Martino, La fine del mondo..., op. cit., 546), es también una consecuencia de vivir en un presente sin resolución, en un presente que se amplía cada vez más, y en el que solo cabe la repetición y la degradación. Este universo beckettiano, en el que las cosas permanecen inmóviles y sin significado, es el universo de escasa «semanticidad» que encontramos en el Prometeo de Kafka. Cfr. H. Blumenberg, Trabajo sobre el mito. Madrid, 2003, 669-672. 
mera transición, y ver el futuro como horizonte de posibilidades» ${ }^{75}$. La primera condición, el hecho de "dejar atrás el pasado», significaba que «el pasado no podía repetirse en el futuro"; la segunda suponía que el presente se iba encogiendo, como decía Baudelaire, «al aumentar el ritmo de los cambiosw; y la tercera que el futuro estaba «abierto" porque se podía intervenir sobre él por medio de la acción presente ${ }^{76}$. El futuro estaba así unido a la idea de cambio acelerado, el cual transformaba el presente en un fugaz instante de tránsito entre el pasado, que permanecía en el recuerdo como experiencia, y el indeterminado futuro, que se abría a todo tipo de expectativas.

Gumbrecht sostiene que, sobre todo a partir de los años setenta del siglo pasado, empieza a admitirse que ha aparecido un nuevo tipo de tiempo histórico, un nuevo cronotopo, ya que parece haberse "congelado", detenido y ensanchado el presente. De forma similar a lo que sucede en las obras de Beckett, el presente pasa más lentamente, es más ancho, porque el futuro redentor ya no llega, o incluso es mejor que no llegue porque adquiere rasgos amenazadores. Influido por la lectura del poeta húngaro János Pilinszki, Gumbrecht describe el presente ancho del nuevo cronotopo como un «arrugarse de lo transitorio». El presente empieza a tener arrugas cuando el tiempo comienza a ralentizarse y a "generar dolor": "el pasado -añade el autor de Después de 1945- se congela, se petrifica, se hace pesado, y rechaza quedarse «atrás», en el lugar que «le corresponde». [...] Entre mudez, arrugas, petrificación, el tiempo deja de avanzar, y el estancamiento reemplaza el progreso y la aceleración ${ }^{\mathbb{Q}}$. Ya no se espera que tenga lugar esa resolución o redención del tiempo que para los modernos daba sentido a la historia ${ }^{77}$. Nuestra época postmoderna deja entonces de ser "futurocéntrica».

Esta tesis contrasta con la que expone Boris Groys sobre nuestro tiempo histórico. En su opinión, no vivimos en un presente que se eterniza, sino en una época que lleva la modernidad hasta sus últimas consecuencias. Para este filósofo alemán, modernidad «significa no tener tiempo, experimentar una permanente escasez, una falta de tiempon, porque cada nueva generación desarrolla sus propios proyectos y, antes de que puedan realizarse, la siguiente generación los abandona por otros nuevos. «En este sentido -advierte Groys-, nuestro presente no es una época posmoderna sino ultramoderna porque es la época en la que la escasez de tiempo [...] se vuelve cada vez más obvia». No hay tiempo para que se establezcan tradiciones, para que se asienten las costumbres: «vemos -concluye el filósofo- todas nuestras tradiciones y estilos de vida condenados a la decadencia y desaparición ${ }^{78}$. En lugar de congelarse -como explica Gumbrecht-, el tiempo se halla en constante mutación. Pero más allá de las considerables diferencias entre Gumbrecht y Groys, ambos se apartan de la moderna filosofía de la historia que cree en el progreso: ya se trate de estancamiento o de cambio permanente, el fin de la historia, en el que las cosas estarán definitivamente en el lugar que

75. H. U. Gumbrecht, Después de 1945..., op. cit., 195.

76. H. U. Gumbrecht, Lento presente. Sintomatología del nuevo tiempo histórico, Madrid, 2010, 47, 45, 31.

77. K. Löwith, El hombre..., op. cit., 315-329.

78. B. Groys, Volverse público. Las transformaciones del arte en el ágora contemporánea, Buenos Aires, 2014, 107. 
les corresponde, parece una utopía inalcanzable. Por un lado, se reconoce que el presente se ha detenido sin que se hayan alcanzado las aspiraciones de la humanidad (Gumbrecht); por otro, se admite que los cambios continuos tampoco nos acercan al final deseado (Groys).

Koselleck ha sido considerado por Gumbrecht y Hartog como el gran teórico del «cronotopo» o del «régimen de historicidad» moderno. A pesar de que no ha teorizado sobre el final de la modernidad, este artículo ha pretendido demostrar que el autor de Futuro pasado proporciona también muchos elementos para reflexionar sobre este final. Su obra sirve para pensar en categorías que, como las de anacronismo, memoria o latencia, ya no son simples instrumentos con los que la estética explica la relación de muchas obras de arte con la historia. En lugar de despreciarlas como categorías marginales para la historiografía, pensamos que son fundamentales para explicar la presente crisis de la modernidad.

Las reflexiones koselleckianas sobre el punto de vista y sobre las dificultades para dejar atrás un pasado que no debería repetirse en el futuro, ponen de relieve las dificultades crecientes, en un contexto en el que se impone el «presentismo», para perseguir los anacronismos. Ciertamente, Koselleck no ha pensado en la posmodernidad, pero sus análisis sobre la «memoria colectiva» y los monumentos levantados después de 1945 hacen referencia a un mundo en el que nuestras expectativas sobre el futuro ya no determinan el sentido de la historia de los hechos pasados. En relación con la memoria, cabe reconocer que las crisis que se suceden tras el final de la Segunda Guerra Mundial, no solo conducen al estancamiento y parálisis que caracteriza al présentisme, al presente ancho, de nuestros días, sino también a los «impulsos y ascensos de la memoria», la cual, a juicio de Hartog, aparece en ocasiones como una «alternativa terapéutica» frente a las opresivas e imperialistas historias nacionales de los vencedores $^{79}$. Así que no todos los signos que apuntan al fin de la modernidad son apocalípticos, como, sin embargo, podría parecer después de leer a Gumbrecht.

Tras el ocaso del pensamiento moderno sobre la historia universal, sobre la Geschichte como «sustantivo colectivo singular» ${ }^{80}$, se abre una concepción postmoderna de la historia, una especie de "poshistoria», que introduce dos novedades en el discurso histórico: la aceptación de vivir con el escándalo de la contingencia y la elaboración de una historia des-singularizada, re-pluralizada. En primer lugar, aceptar dicho «escándalo» significa que debemos desembarazarnos de la idea de un final que ponga felizmente término a la concepción de la historia como el tiempo en que el hombre, como decía el antropólogo y filósofo De Martino, debe hacer frente al riesgo radical de no ser en ningún mundo posible. Este riesgo, sin embargo, es inherente a la contingencia, a la historicidad, del ser humano, y, por tanto, insuperable. Por lo demás, no se nos escapa que el desenmascaramiento de esta ficción consoladora, la de una historia que aspira a parecerse a su contrario, a la eternidad, puede ser una de las principales razones del «malestar» del hombre contemporáneo. En segundo lugar, cabe decir que la filosofía moderna ha tendido a la simplificación, a elaborar una historia unilineal, mientras que los conceptos filosóficos relacionados con la «poshistoria» o la posmodernidad tienden

79. R. Silva, "Memoria e historia: entrevista con François Hartog", Historia crítica, 48, 2012, 209.

80. R. Koselleck, historia/Historia, Madrid, 2004. 
Monográfico | Koselleck y los márgenes estéticos de la historia: anacronismo, memoria y latencia

a introducir una mayor complejidad. Desde este último enfoque, la historia de la humanidad se compone de una pluralidad irreductible de historias, que, como sucede con el centauro doble del filme de Pasolini, solo podemos yuxtaponer, pero ya no integrar, como quisieron los modernos, dentro de un mismo discurso racional y de una misma línea de evolución. 